\title{
A case-control evaluation of the effect of breast cancer screening in the United Kingdom trial of early detection of breast cancer
}

\author{
S M Moss, M E Summerley, B T Thomas, R Ellman, J O P Chamberlain
}

\begin{abstract}
Objective-The aim was to assess the extent to which selection bias affects a casecontrol study of breast cancer screening in which attenders and non-attenders for screening are compared.

Design-There were two retrospective case-control studies, one estimating the risk of death from breast cancer in women in the screening district relative to those in the comparison district (study $A$ ), the second estimating the relative risk for women who had ever been screened compared with women who had never been screened in the screening district alone (study B). For cases and controls in study $B$, the women's screening history was summarised for the time period from date of entry to diagnosis of the case, or the equivalent time from date of entry for the matched controls. For cases detected by screening, the screen at which cancer was detected was included in the screening history.
\end{abstract}

Subjects-Cases were deaths from breast cancer in women with disease diagnosed after entry to the trial, up to 31 December 1986 or a maximum of seven years from date of entry, in one of the screening districts (Guildford) and one of the comparison districts (Stoke) participating in the UK Trial of Early Detection of Breast Cancer: study A: 198 deaths in Guildford and Stoke; study B: 51 deaths in Guildford only. There were five age matched controls for each case, with length of follow up at least as great as the time from entry to death of the case.

Main results-The estimate of the risk of death from breast cancer in the screening district relative to the comparison district from study $A$ was 0.76 , thus implying a reduction of $24 \%$ in the screening district, similar to that obtained from a cohort analysis of data from the two districts. In contrast, the relative risk in study $B$ for ever $v$ never screened women was 0.51 , which, taking the $72 \%$ compliance into account, would result in a relative risk of 0.65 for the screening district if there were no selection bias. The risk of breast cancer mortality in the never screened relative to the comparison district was $1 \cdot 13$, despite the fact that incidence rates in the two populations were similar. This suggested that cancers in the never screened group had a particularly poor prognosis, contributing to selection bias.

Conclusions-The possible existence of selection bias should lead to caution in interpretation of the results of case-control studies of the effect of breast cancer screening on mortality.

f Epidemiol Community Health 1992; 46: 362-364

The evidence to date for the effectiveness of screening in reducing mortality from breast cancer has come from randomised trials, ${ }^{1-4}$ from population based studies for which control populations were available, ${ }^{5}$ and from case-control studies conducted for population based screening programmes with no control population. ${ }^{6-8}$

The United Kingdom trial of early detection of breast cancer (TEDBC), while not a randomised trial, included four separate "comparison" populations, from which the same data on breast cancer incidence and mortality were collected as in the four "intervention" districts. ${ }^{9}$ The first results on mortality from this trial showed a reduction in breast cancer mortality in the two districts offering annual screening of $14 \%$ relative to the comparison districts; this reduction increased to $20 \%$ when the breast cancer mortality in the different districts in the 10 year period before the start of the trial was taken into account. $^{5}$

The present study is a case-control evaluation comparing one of the screening districts with one of the comparison districts in this trial. A second case-control evaluation was conducted solely within the screening district, and compared screened and unscreened women. The purpose of undertaking two studies was to assess the extent of selection bias in the latter comparison. A subsidiary aim was to collect additional information on risk factors in order to estimate any underlying difference between the two districts and the extent to which such differences might have affected the results of the trial.

\section{Methods}

The methodology of the trial has been described in detail elsewhere. The present study includes data from Guildford, where screening was offered to all women aged 45-64 years by mammography and clinical examination every two years, with clinical examination in the intervening years; and Stoke-on-Trent, which acted as one of the comparison districts. In both districts the entire trial population has been flagged at the National Health Service Central Registry, which supplies the TEDBC coordinating centre with information on all breast cancer registrations and deaths. In Guildford, $72 \%$ of women accepted the initial invitation to screening and information on a number of risk factors for breast cancer was 
collected each time a woman attended for screening. Similar data were collected when cases of breast cancer were notified to the trial.

In study $\mathbf{A}$, cases are taken as all deaths from breast cancer in the two districts in cases diagnosed after entry to the trial, occurring up to 31 December 1986, or seven years in the trial where this was earlier. Thus the cases correspond to those deaths included in the first published mortality results from the TEDBC. ${ }^{5}$

For each case, five controls were drawn from the pooled population of the two districts, matched on age at entry to the trial within six months. The controls were all free from breast cancer at the time of diagnosis of the case, and alive (although not necessarily disease free) at the time of death of the case. Women in Stoke-onTrent all entered the trial on 1st January 1980, whereas in Guildford entry was staggered over a 26 month period between 1979 and 1981. To circumvent this problem, time has been measured from the date of entry to the trial of each case or control, rathèr than actual calendar time, with the additional restriction that controls must have a length of follow up at least as great as the time from entry to death of the case.

For the Guildford cases and their matched controls, screening attendance has been defined as any routine screening clinic visits in the period from entry to the trial up to the time of diagnosis of the case. For cases detected by screening, the screening visit at which cancer was diagnosed is included in this definition.

A matched analysis was carried out, using the Mantel-Haenszel method, of the effect on breast cancer Inortality of being in the population offered screening. The result of this analysis was compared with a cohort analysis including only these two districts. A logistic regression analysis with conditional likelihood functions was then used to include the effect of screening attendance; the analysis was carried out using the computer program PECAN. ${ }^{10}$

For study B, a new set of age matched controls for the Guildford cases only was drawn, this time from the Guildford population alone.

The screening history for cases and controls was summarised as for study $A$, and a matched analysis carried out of the effect on breast cancer mortality of ever attending for screening compared with non-attenders.

A postal questionnaire was sent to control women in order to collect information on risk

Table I Distribution of case-control combinations by screening and comparison population (study $A$ )

\begin{tabular}{|c|c|c|c|c|c|c|c|}
\hline \multirow[b]{2}{*}{ Case } & \multicolumn{6}{|c|}{ No of controls in Guildford } & \multirow[b]{2}{*}{ Tota } \\
\hline & 0 & 1 & 2 & 3 & 4 & 5 & \\
\hline $\begin{array}{l}\text { Guildford } \\
\text { Stoke-on-Trent }\end{array}$ & $\begin{array}{r}8 \\
21 \\
\end{array}$ & $\begin{array}{l}17 \\
57\end{array}$ & $\begin{array}{l}18 \\
43 \\
\end{array}$ & $\begin{array}{r}6 \\
18 \\
\end{array}$ & $\begin{array}{l}2 \\
4 \\
\end{array}$ & $\begin{array}{l}0 \\
4 \\
\end{array}$ & $\begin{array}{r}51 \\
147 \\
\end{array}$ \\
\hline Odds ratio $=$ & $8)+(4$ & $\times 17)$ & $-(3 x$ & $8)+$ & $2 \times 6)$ & $+(1 \times$ & \\
\hline
\end{tabular}

Table II Breast cancer incidence and mortality: cohort analysis of Stoke-on-Trent and Guildford populations

\begin{tabular}{lllll} 
& & & & \\
& Women in & Person- & $\begin{array}{l}\text { Incidence } \\
\text { rate per } \\
\text { initial } \\
\text { population }\end{array}$ & $\begin{array}{l}\text { years to } \\
\text { ytandardised } \\
\text { mortality rate }\end{array}$ \\
& 31.12 .86 & - years & $\begin{array}{l}\text { person } \\
\text { per 1000 } \\
\text { person-years }\end{array}$ \\
\hline Stoke-on-Trent & 48324 & 327170 & 1.6 & 0.45 \\
Guildford total & 22647 & 148240 & 2.6 & 0.34 \\
attenders & & 114026 & 2.9 & \\
non-attenders & & 34214 & 1.7 & \\
\hline
\end{tabular}

factors for breast cancer comparable to that available for cases. The intention was to adjust the analysis for any difference in risk of getting breast cancer between Guildford and Stoke-on-Trent. However, response was only $43 \%$ and many returned questionnaires were incomplete so that this adjustment was not possible.

\section{Results}

The cases for study A comprised 198 breast cancer deaths, of which $51(26 \%)$ were in the Guildford population offered screening. Of the 990 age matched controls, $312(32 \%)$ were in the Guildford population, giving a crude relative risk of death from breast cancer of 0.75 in Guildford compared with Stoke-on-Trent.

Table I summarises the results of the matched analysis; the relative risk of death from breast cancer in the population offered screening is 0.76 (95\% confidence interval 0.54-1.08). Table II gives the cohort data for the two populations. When these data are standardised for year in trial as well as for age (since the Guildford women have variable length of follow up) the relative risk of breast cancer death for Guildford compared with Stoke-on-Trent is 0.79 . Table III shows the numbers of Guildford cases and controls according to screening attendance. The conditional logistic regression analysis gives relative risks, with $95 \%$ confidence intervals, of $1.17(0.71-1.93)$ and 0.58 $(0.38-0.90)$ for women who had never or had ever been screened compared with those in Stoke-onTrent not offered screening. The relative risk for the ever screened compared with the never screened in Guildford is 0.50 (95\% confidence interval $0.27-0.92$ ).

Table IV gives the results of study $B$, the "internal" case-control study, within the Guildford population alone; $55 \%(28 / 51)$ of the cases and $71 \%(181 / 255)$ of the controls had attended for screening at least once. The matched analysis gives a relative risk of $0.51 \quad(95 \%$ confidence interval $0.27-0.98$ ) for women ever screened compared with those never screened, which is very similar to the estimate of 0.50 obtained from the similar analysis using different controls in study A.

Table III Comparison of risk in Guildford and Stokeon-Trent according to screening history (study A)

\begin{tabular}{llll}
\hline \multicolumn{1}{c}{ Stoke-on-Trent } & \multicolumn{1}{l}{ Guildford } \\
\cline { 3 - 4 } & & Never screened & Ever screened \\
\hline Cases & 147 & 23 & 28 \\
Controls & 678 & 91 & 221 \\
Relative risk & 1.0 & $1 \cdot 17$ & 0.58 \\
\hline
\end{tabular}

Table IV Distribution of case-control combinations by screening history (study B)

\begin{tabular}{|c|c|c|c|c|c|c|c|}
\hline \multirow[b]{2}{*}{ Cases } & \multicolumn{6}{|c|}{ No of controls-ever screened } & \multirow[b]{2}{*}{ Total } \\
\hline & 0 & 1 & 2 & 3 & 4 & 5 & \\
\hline $\begin{array}{l}\text { Ever screened } \\
\text { Never screened }\end{array}$ & 1 & $\begin{array}{l}2 \\
0\end{array}$ & $\begin{array}{l}3 \\
1\end{array}$ & $\begin{array}{l}7 \\
8\end{array}$ & $\begin{array}{l}6 \\
8\end{array}$ & $\begin{array}{l}9 \\
5\end{array}$ & $\begin{array}{l}28 \\
23\end{array}$ \\
\hline \multirow{2}{*}{ Odds ratio $=$} & 1) + & x & $3 x$ & + & 7) & $(\times 6)$ & \multirow{2}{*}{$=0.5$} \\
\hline & & & & & & $\times 5)$ & \\
\hline
\end{tabular}

\section{Discussion}

Even where no selection bias is present, it should be borne in mind that the relative risk in women who had ever been screened compared with those 
never screened does not predict the likely effect of screening on a population unless full compliance can be expected. With no selection bias and a compliance of $72 \%$, a relative risk of 0.51 in screened women would result in a $35 \%(=0.72 \times[1-0.51] \times 100)$ overall mortality reduction in the population. In study $A$, however, the reduction for Guildford was found to be $25 \%$, very similar to the results from the cohort analysis. It would therefore appear from the results of this study that a comparison of screened and never screened women within the population offered screening (study B) gives a biased estimate of the overall benefit of screening to the population.

However, in study A the relative risk in the non-attenders for screening compared with those not offered screening did not differ significantly from $1 \cdot 0$, so that the excess reduction in screened women could be due to chance. The equality of breast cancer incidence in non-attenders for screening with that in a control population has been used elsewhere as evidence against the existence of selection bias $^{8}$; likewise other studies have used risk factors associated with increased incidence to adjust for possible bias, though these may not reflect relevant determinants of delay in presentation or risk of death. The attempt in the present study to adjust for differences in risk factors between the two districts was unsuccessful due to the incompleteness of the data collected. However, breast cancer mortality in the 10 year period before the start of the trial was similar in the two districts. Since the incidence rate in the women who had never been screened in Guildford was similar to that in the Stoke-on-Trent population as a whole, it appears that in this instance the bias results from a tendency for breast cancers in never screened women to have a poor prognosis relative to those in a comparison population. In fact $83 \%$ of the deaths in non-attenders were of women with advanced (stage III or IV) cancers at diagnosis compared with $53 \%$ of those who died in Stoke-on-Trent. A recent study has found higher breast cancer case fatality rates in women in manual as opposed to non-manual social classes, despite very similar incidence rates. ${ }^{11}$

Two other case-control studies of breast cancer screening have shown similar relative risks in screened women compared with women who had never been screened: 0.48 in the study from Nijmegen ${ }^{6}$ and 0.53 in that from Florence. ${ }^{8}$ The Utrecht study, by contrast, gave a relative risk of $0 \cdot 30 .^{7}$ The design of the latter study was slightly different, in that cases diagnosed after the start of the screening programme but prior to their date of personal invitation were included. This leads to comparatively low percentages screened in both the cases and controls, which should tend to underestimate the benefit of screening unless such cases were affected by publicity surrounding the introduction of the screening programme. The other point of note is that the Utrecht study was restricted to women aged 50 years and over at time of entry, which is the age group in which randomised studies have tended to show a benefit. The confidence intervals in all three studies were wide, with that for Nijmegen including unity (although a later analysis with additional cases gave a relative risk of 0.51 with $95 \%$ confidence interval of $0 \cdot 26-0 \cdot 99^{12}$ ). Further, a case-control study with the same design as that in Nijmegen, conducted within the study population of a randomised trial in Malmo which showed no overall benefit in the group offered screening, ${ }^{3}$ has shown a relative risk of $0.42(95 \% \mathrm{CI} 0.22-0.78)$ in attenders $v$ non-attenders for screening. ${ }^{13}$

A case-control study of the effect of education in breast self examination in Nottingham ${ }^{14}$ showed an overall relative risk of 0.70 in women attending for education. The attendance at education sessions on self examination was $49 \%$ as a result of two rounds of invitations. However there is no difference between the survival of the whole case series and that of a series of historical controls. Further, just under half of the population included in this study also formed one of the breast self examination districts in the TEDBC. The TEDBC showed the risk of breast cancer mortality in the two breast self examination centres combined to be 1.10 relative to the comparison centres (with Nottingham having the higher risk of the two). The breast cancer mortality rate in the Nottingham non-attenders was higher than in the comparison districts, again indicating selection of poor prognosis cases into the non-attenders group.

The possible existence of selection bias should lead to caution in the interpretation of the results from other case-control studies of breast cancer screening.

We thank Nicki Adams, Carol Munt, Pat Pocock, and Margaret Snigorska for clerical assistance.

1 Shapiro S, Venet W, Strax P, Venet L, Roeser R. Ten to fourteen-year effect of screening on breast cancer mortality. f Natl Cancer Inst 1982; 69: 349-55.

2 Tabar L, Gad A, Holmberg LH, et al. Reduction in mortality from breast cancer after mass screening with mortality from breast cancer after mass

3 Andersson I, Aspergen K, Janzon L, et al. Mammographic Andersson 1, Aspergen $K$, Janzon L, et al. Mammographic mammographic screening trial. $B M F$ 1988; 297: 943-50.

4 Roberts MM, Alexander FE, Anderson TJ, et al. Edinburgh trial of screening for breast cancer: mortality at 7 years. Lancet 1990; 335: 241-6.

5 UK Trial of Early detection of Breast Cancer Group. First results of mortality reduction in the UK Trial of Early Detection of Breast Cancer. Lancet 1988; ii: 411-6.

6 Verbeek ALM, Hendricks JHCL, Holland R, Mravunac M, Sturmans F, Day NE. Reduction in breast cancer mortality through mass screening with modern mammography (First results of the Nijmegen Project 1975-81.) Lancet 1984; i: 1222-4.

7 Collette HJA, Day NE, Rombach JJ, de Waard F Evaluation of screening for breast cancer in a nonrandomised study (the DOM Project) by means of a case-control study. Lancet 1984; i: 1224-5.

8 Palli D, Rosselli del Turco M, Buiatti E, et al. A case-control study of the efficacy of a non-randomised breast cancer screening program in Florence (Italy). Int $\mathcal{F}$ Cancer 1986 38: $501-4$.

9 UK Trial of Early Detection of Breast Cancer Group. Trial of early detection of breast cancer: description of method. Br 尹 Cancer 1981; 44: 618 .

10 Storer BE, Wacholder S, Breslow NE. Maximum likelihood fitting of general relative risk models to stratified data. $A p p$ Stat 1983; 32: 172-81.

11 Kogevinas E. OPCS longitudinal study: socio-demographic differences in cancer survival. London: HMSO, 1990: Series LS, No 5 .

12 Verbeek ALM, Hendricks JHCL, Holland R, Mravunac M, Sturmans F. Mammographic screening and breast cancer
mortality: age-specific effects in Nijmegen Project 197582. Lancet 1985; i: 865-6.

13 Gulberg B, Andersson I, Janzon L, Ranstam J. Screening mammography. Lancet 1991; 337: 244.

14 Locker AP, Caseldine J, Mitchell AK, Blamey RW, Roebuck EJ, Elston CW. Results from a seven-year programme of breast self-examination in 89,010 women. $\mathrm{Br}$ f Cancer 1989; 60: 401-5. 